\title{
Innovative Endoscopic Technologies in the Complex Treatment of Patients with Unstable Stopped Gastroduodenal Bleeding
}

\author{
Evgeniy F. Cherednikov, $\mathrm{PhD}, \mathrm{ScD}^{1}$; Sergey V. Barannikov, $\mathrm{PhD}^{1}$; \\ Igor S. Yuzefovich, $\mathrm{PhD}^{1}$; Galina V. Polubkova, $\mathrm{PhD}^{1}$; Yuri V. Maleev, $\mathrm{PhD}, \mathrm{ScD}^{2}$; \\ Irina V. Volkova ${ }^{3}$; Anastasiya T. Vysotskaya, $\mathrm{PhD}^{1}$; Oleg V. Strygin, $\mathrm{PhD}^{3}$; \\ Evgeniy S. Ovsyannikov, $\mathrm{PhD}, \mathrm{ScD}^{1 *}$ \\ ${ }^{1}$ Voronezh State Medical University named after N. N. Burdenko \\ ${ }^{2}$ Voronezh Basic Medical College \\ ${ }^{3}$ Voronezh City Clinical Emergency Hospital №1 \\ Voronezh, the Russian Federation
}

\begin{abstract}
Background: The aim of our research was to improve the results of treatment of patients with unstable bleeding gastroduodenal ulcers through the use of innovative endoscopic technologies in the complex treatment of gastroduodenal bleeding.

Methods and results: The study included 132 patients with unstable ulcerative gastroduodenal bleeding. Among all patients with gastroduodenal bleeding, there were $95(71.96 \%)$ men and 37(28.04\%) women. The average age of patients was $56.1 \pm 18.45$ years. Among the sources of gastroduodenal ulcer bleeding, duodenal ulcers complicated by bleeding predominated were observed in 77(58.3\%) patients, bleeding gastric ulcers and ulcers of gastroenteroanastomosis areas in $49(37.7 \%)$ and $6(4.6 \%)$ patients, respectively. According to the endoscopic classification (J. Forrest, 1974), continued bleeding (Forrest Ia-Ib) was observed in $44(33.3 \%)$ patients, threat of rebleeding (Forrest IIa-IIb) in 88(66.7\%) patients.

All patients were divided, by random sampling, into two equivalent groups: the main group ( $\mathrm{MG}, \mathrm{n}=66)$ and the comparison group $(\mathrm{CG}, \mathrm{n}=66)$. In the treatment of MG patients, an individual approach was applied that used the injection of $\varepsilon$-aminocaproic acid, argon-plasma coagulation, and the endoscopic pneumatic applications of hemostatic agents (Zhelplastan and the patient's platelet-rich auto-plasma) and granular sorbents (Aseptisorb-A, Aseptisorb-D). In CG, traditional methods of endoscopic hemostasis (injection method with $\varepsilon$-aminocaproic acid and vasoconstrictor drugs, argon plasma coagulation, etc.) were used without granular sorbents and innovative hemostatic agents.

In patients with the Forrest Ia-Ib bleeding, primary endoscopic hemostasis was achieved in $95.2 \%$ of cases in the MG and in $91.3 \%$ of cases in the CG $(P>0.05)$. In patients with t he Forrest IIa-IIb bleeding, effectiveness of endoscopic prevention of recurrent bleeding was achieved in $95.5 \%$ of cases in the $\mathrm{MG}$ and in $81.4 \%$ of cases in the $\mathrm{CG}(P=0.047)$. Mortality rate was $1.5 \%$ in the MG and $4.5 \%$ in the CG $(P>0.05)$. In the MG and CG, the overall frequency of recurrent bleeding from gastroduodenal ulcers, the operational activity, and the length of hospital stay were $15.2 \%$ and $4.5 \%(P=0.041), 12.1 \%$ and $1.5 \%(P=0.033)$, and $11.1 \pm 0.6$ days and $9.2 \pm 0.4$ days $(P<0.01)$, respectively.

Conclusion: The developed method for the complex treatment of patients with unstable gastroduodenal bleeding, based on the optimization of emergency and preventive endoscopic hemostasis, indicates that the use of therapeutic endoscopy to prevent bleeding recurrences with hemostatic agents and granular sorbents improves the reliability of endoscopic hemostasis, reduces the frequency of hemorrhage relapses and the number of emergency operations, as well as a length of hospital stay. (International Journal of Biomedicine. 2021;11(1):24-28.)
\end{abstract}

Key Words: gastroduodenal hemorrhage $\bullet$ endoscopic hemostasis $\bullet$ granular sorbents $\bullet$ hemostatic agents

For citation: Cherednikov EF, Barannikov SV, Yuzefovich IS, Polubkova GV, Maleev YuV, Volkova IV, Vysotskaya AT, Strygin OV, Ovsyannikov ES. Innovative Endoscopic Technologies in the Complex Treatment of Patients with Unstable Stopped Gastroduodenal Bleeding. International Journal of Biomedicine. 2021;11(1):24-28. doi:10.21103/Article11(1)_OA4 


\section{Introduction}

The treatment of gastroduodenal bleeding is one of the most acute problems in the practice of surgeons, endoscopists, gastroenterologists, resuscitators, etc. ${ }^{(1-6)}$

Unstable stopped gastroduodenal bleeding is associated with frequent relapses of bleeding and urgent surgery. ${ }^{(7-9)}$ More than half of all cases of gastroduodenal bleeding are caused by ulcerative lesions of the stomach and duodenum..$^{(10,11)}$

V.S. Savelyev notes that if the ulcer is closed with a clot (Forrest $\mathrm{IIb}$ ), then a relapse of bleeding is possible in $20 \%$ of patients, and upon detection of a large vessel in an ulcer (Forrest IIa), recurrence of bleeding occurs in $40 \%$ of patients. When the patient has continued bleeding (Forrest Ia-Ib) or blood flow from under a clot, which was able to stop during endoscopic hemostasis, bleeding recurrence is observed in $50 \%$ of patients. ${ }^{(12)}$

In patients with unstable stopped gastroduodenal bleeding, it is important not only to stop the bleeding, but also to create conditions for reducing the risk of recurrent hemorrhage, as well as for the rapid healing of the ulcer defect as a possible source of complications. ${ }^{(13-16)}$

In this regard, the search for the new cytoprotective agents for the protection of the ulcerative defects, thrombosed vessel, and a zone of coagulation necrosis from aggressive gastric juice, as well as the development of the new methods for the prevention of the recurrent gastroduodenal ulcer bleeding are an urgent task. ${ }^{(17,18)}$

The aim of our research was to improve the results of treatment of patients with unstable bleeding gastroduodenal ulcers through the use of innovative endoscopic technologies in the complex treatment of gastroduodenal bleeding.

\section{Materials and Methods}

A clinical study was conducted in the Voronezh City Specialized Center for the treatment of patients with gastrointestinal bleeding. The study was approved by the Ethics Committee of Voronezh State Medical University named after N.N. Burdenko. Written informed consent was obtained from each patient.

The study included 132 patients with unstable ulcerative gastroduodenal bleeding. Among all patients with gastroduodenal bleeding, there were 95(71.96\%) men and $37(28.04 \%)$ women. The average age of patients was $56.1 \pm 18.45$ years.

Peptic ulcer disease complicated by bleeding was observed in 72(54.5\%) patients (Table 1). In 60(45.5\%) patients, acute symptomatic ulcers were the cause of bleeding. Among the sources of gastroduodenal ulcer bleeding, duodenal ulcers complicated by bleeding predominated were observed in $77(58.3 \%)$ patients, bleeding gastric ulcers and ulcers of gastroenteroanastomosis areas in $49(37.7 \%)$ and 6(4.6\%) patients, respectively.

According to the endoscopic classification, ${ }^{(19)}$ continued bleeding (Forrest Ia-Ib) was observed in $44(33.3 \%$ ) patients, threat of rebleeding (Forrest IIa-IIb) in 88(66.7\%) patients.

According to the severity of blood loss (A.L.Gorbashko,
$1982),{ }^{(20)}$ the patients were divided as follows: mild severity was observed in $42(31.8 \%)$, moderate in $63(47.7 \%)$ and severe in $27(20.5 \%)$.

All patients were divided, by random sampling, into two equivalent groups: the main group $(\mathrm{MG}, \mathrm{n}=66)$ and the comparison group ( $\mathrm{CG}, \mathrm{n}=66$ ). Patients were comparable in etiology of ulcerative bleeding, age, gender, degree of severity of bleeding, nature of bleeding according to endoscopic classification, and duration of observations.

Table 1.

Clinical characteristics of the study groups

\begin{tabular}{|l|c|c|c|c|c|}
\hline \multicolumn{1}{|c|}{ Indicator } & $\begin{array}{c}\text { MG } \\
(\mathrm{n}=66)\end{array}$ & $\begin{array}{c}\text { CG } \\
(\mathrm{n}=66)\end{array}$ & $P$ & $\begin{array}{c}\text { Total } \\
(\mathrm{n}=132)\end{array}$ \\
\hline \multicolumn{5}{|c|}{ Type of gastroduodenal ulcers } \\
\hline $\begin{array}{l}\text { Peptic ulcer disease of } \\
\text { the stomach and } \\
\text { duodenum }\end{array}$ & $39(59.1 \%)$ & $33(50 \%)$ & $>0.05$ & $72(54.5 \%)$ \\
\hline Acute symptomatic ulcers & $27(40.9 \%)$ & $33(50 \%)$ & $>0.05$ & $60(45.5 \%)$ \\
\hline \multicolumn{5}{|c|}{ Localization of the source of bleeding } \\
\hline Duodenal ulcers & $37(56.1 \%)$ & $40(60.6 \%)$ & $>0.05$ & $77(58.3 \%)$ \\
\hline Stomach ulcers & $27(40.9 \%)$ & $22(33.3 \%)$ & $>0.05$ & $49(37.1 \%)$ \\
\hline $\begin{array}{l}\text { Gastroentero- } \\
\text { anastomosis ulcers }\end{array}$ & $2(3.0 \%)$ & $4(6.1 \%)$ & $>0.05$ & $6(4.6 \%)$ \\
\hline Type of bleeding (J. Forrest, 1974) \\
\hline Forrest Ia-Ib & $21(31.8 \%)$ & $23(34.8 \%)$ & $>0.05$ & $44(33.3 \%)$ \\
\hline Forrest IIa-IIb & $45(68.2 \%)$ & $43(65.2 \%)$ & $>0.05$ & $88(66.7 \%)$ \\
\hline Mild severity of blood loss (A. I. Gorbashko, 1982) \\
\hline Severe & $32(48.5 \%)$ & $31(47.0 \%)$ & $>0.05$ & $63(47.7 \%)$ \\
\hline
\end{tabular}

In the treatment of MG patients, an individual approach was applied that used the endoscopic pneumatic applications of hemostatic agents and a granular sorbent in the complex endoscopic treatment of gastroduodenal ulcers complicated by bleeding. In particular, in patients with ongoing hemorrhage (Forrest Ia-Ib), active bleeding was stopped first by injection with $\varepsilon$-aminocaproic acid, then with vasoconstrictor drugs, followed by argon-plasma coagulation; and then the powderlike hemostatic agent Zhelplastan (Gelplastan) and granular sorbent Aseptisorb-D were pneumatically insufflated onto the defect area (Patent RF №2633588). ${ }^{(21)}$

In patients with the threat of rebleeding (Forrest IIaIIb), the argon-plasma coagulation of the thrombosed vessel 
(Forrest IIa) was first performed, and in Forrest IIb, the clot was first removed from the ulcer defect by washing it, then the argon-plasma coagulation of the bleeding source was also performed. After that, with the help of an insufflator, Aseptisorb-A powder was applied to the area of these ulcerative defects, followed by the application of the patient's platelet-rich auto-plasma (Patent RF № 2632771).(22)

In $\mathrm{CG}$, traditional methods of endoscopic hemostasis (injection method with $\varepsilon$-aminocaproic acid and vasoconstrictor drugs, argon-plasma coagulation, etc.) were used without platelet-rich auto-plasma and granular sorbents. After that, the complex treatment of patients in the MG and CG did not differ.

The main criteria in assessing the results of treatment were both clinical and endoscopic indicators: the timing of the final hemostasis, the frequency of rebleeding, dynamic monitoring of the size of ulcerative defects, the quality of healing of ulcers, the presence of emergency operations, hospital length of stay, and mortality rates.

The statistical analysis was performed using the statistical software Microsoft Excel. Baseline characteristics were summarized as frequencies and percentages for categorical variables and as mean \pm SEM for continuous variables. For data with normal distribution, inter-group comparisons were performed using Student's t-test. Differences of continuous variables departing from the normal distribution, even after transformation, were tested by the Mann-Whitney U-test. For data with normal distribution, inter-group comparisons were performed using Student's t-test. Group comparisons with respect to categorical variables are performed using chi-square tests with Yates correction or, alternatively, Fisher's exact test when expected cell counts were less than 5 . A probability value of $P<0.05$ was considered statistically significant.

\section{Results and Discussion}

When evaluating the results of treatment of patients in the MG with unstable bleeding, it was noted that primary endoscopic hemostasis was achieved in 20(95.2\%) patients with the Forrest Ia-Ib bleeding. Effectiveness of endoscopic prevention of recurrent bleeding in patients with the Forrest IIa-IIb bleeding was noted in 43(95.6\%) cases. Recurrence of ulcerative bleeding was observed in $3(4.50 \%)$ cases. Repeated endoscopic hemostasis was effective in 2 cases. An 80-year-old patient was operated on urgently due to the failure of repeated endoscopic hemostasis. This patient died in the presence of severe concomitant pathology and increasing multiple organ failure in the postoperative period.

Clinical observations showed that in patients of the MG who received endoscopic treatment according to the developed technique, after pneumo-insufflation on a bleeding ulcer defect of granular sorbents in combination with hemostatic agents, followed by the application of platelet-rich auto-plasma, the granular sorbent swelled, turning into a soft elastic hydrogel that was tightly fixed in the area of the bleeding source due to its properties, protecting it from the effects of aggressive factors of the gastric and duodenal contents. This soft elastic hydrogel lay, as "a protective dressing," showed a double effect - local hemostatic and cytoprotective, preventing the resumption of bleeding and contributing to the favorable course of the reparative process.

In the CG, primary endoscopic hemostasis was achieved in $21(91.3 \%)$ patients with the Forrest Ia-Ib bleeding. Effectiveness of endoscopic prevention of recurrent bleeding in patients with the Forrest IIa-IIb bleeding was noted in $35(81.4 \%)$ cases. Among 23 patients with the Forrest Ia-Ib bleeding, 2 patients were operated on an emergency basis. Recurrence of ulcerative bleeding was observed in 10(15.2\%) cases. Repeated endoscopic hemostasis was effective in 3 cases and 5 patients were operated on urgently due to recurrent profuse bleeding, of which 3 patients died in the postoperative period. One patient in the delayed order was carried out resection of the stomach.

The final results of the treatment of patients are presented in Table 2.

Table 2.

Clinical effectiveness of the treatment of patients unstable bleeding gastroduodenal ulcers in the study groups

\begin{tabular}{|l|c|c|c|}
\hline \multicolumn{1}{|c|}{ Indicator } & $\mathrm{MG}$ & $\mathrm{CG}$ & $P$-value \\
\hline $\begin{array}{l}\text { The effectiveness of } \\
\text { primary endoscopic } \\
\text { hemostasis in Forrest } \\
\text { Ia-Ib }\end{array}$ & $\begin{array}{c}20 \\
(95.2 \% \text { in } \\
\text { relation to } \\
\mathrm{n}=21)\end{array}$ & $\begin{array}{c}21 \\
(91.3 \% \text { in } \\
\text { relation to } \\
\mathrm{n}=23)\end{array}$ & $P>0.05$ \\
\hline $\begin{array}{l}\text { The effectiveness of } \\
\text { endoscopic prevention } \\
\text { of recurrent bleeding in } \\
\text { Forrest IIa-IIb }\end{array}$ & $\begin{array}{c}43 \\
(95.5 \% \text { in } \\
\text { relation to } \\
\mathrm{n}=45)\end{array}$ & $\begin{array}{c}35 \\
(81.4 \% \text { in } \\
\text { relation to } \\
\mathrm{n}=43)\end{array}$ & $P=0.047$ \\
\hline $\begin{array}{l}\text { The frequency of } \\
\text { recurrent bleeding }\end{array}$ & $\begin{array}{c}3(4.5 \%) \\
10(15.2 \%)\end{array}$ & $P=0.041$ \\
\hline $\begin{array}{l}\text { The mean interval for } \\
\text { recurrent bleeding, days }\end{array}$ & $3.5 \pm 0.56$ & $3.27 \pm 0.27$ & $P>0.05$ \\
\hline Operations & $1(1.5 \%)$ & $8(12.1 \%)$ & $P=0.033$ \\
\hline Mortality & $1(1.5 \%)$ & $3(4.5 \%)$ & $P>0.05$ \\
\hline $\begin{array}{l}\text { Length of hospital stay, } \\
\text { days }\end{array}$ & $9.2 \pm 0.4$ & $11.1 \pm 0.6$ & $P<0.01$ \\
\hline
\end{tabular}

Thus, the developed method for treatment of ulcerative gastroduodenal bleeding with the combined use of cytoprotective granular sorbents and local hemostatics in the complex therapy of patients with unstable bleeding gastroduodenal ulcers, provides reliable primary hemostasis in $95.2 \%$ of cases, increases the effectiveness of endoscopic prevention of recurrent hemorrhages from $81.4 \%$ to $95.5 \%$ ( $P=0.047)$, reduces the overall frequency of recurrent bleeding from gastroduodenal ulcers from $15.2 \%$ to $4.5 \%(P=0.041)$, decreases the operational activity from $12.1 \%$ to $1.5 \%$ $(P=0.033)$ and the length of hospital stay from $11.1 \pm 0.6$ days to $9.2 \pm 0.4$ days $(P<0.01)$. 


\section{Conclusion}

The developed methodology for the complex treatment of patients with unstable bleeding, based on the optimization of emergency and preventive endoscopic hemostasis indicates that the use of therapeutic endoscopy to prevent bleeding recurrences with hemostatic agents and granular sorbents improves the reliability of endoscopic hemostasis, reduces the frequency of hemorrhage relapses and the number of emergency operations, as well as a length of hospital stay.

\section{Acknowledgments}

We gratefully acknowledge the contributions of patients to this study.

\section{Competing Interests} interests.

The authors declare that they have no competing

\section{Sources of Funding}

This work was supported by the Council on Grants of the President of the Russian Federation for State Support of Young Scientists and Leading Scientific Schools (Grant MK1069.2020.7).

ClinicalTrials.gov Identifier: NCT04239118 (New Technologies for Endoscopic Treatment of Bleeding Gastroduodenal Ulcers) https://clinicaltrials.gov/ct2/show/ NCT04239118

\section{References}

1. Budnevsky AV, Cherednikov EF, Popov AV, Ovsyannikov ES, Kravchenko AY, Fursov KO. A Complex Multidisciplinary Approach to Prevention Gastro-duodenal Bleeding in Patients of General Hospital. International Journal of Biomedicine. 2017;7(3):204-207. doi: 10.21103/Article7(3)_OA8

2. Cherednikov EF, Deryaeva OG, Adianov VV, Ovchinnikov IF, Popov AV. [Modern trends of diagnosis and treatment of patients with gastrointestinal bleeding in the centre]. System Analysis and Management in Biomedical Systems. 2014;13(2):426-431. [Article in Russian].

3. Cherednikov EF, Maleev YuV, Chernyh AV, Litovkina TE, Bondarenko AA, Cherednikov EE, Popov AV. [Current views on the diagnosis, treatment, and prevention of ruptured hemorrhagic syndrome (Mallory-Weiss syndrome)]. Journal of New Medical Technologies. 2016;23(4):161-172. [Article in Russian].

4. Baev VE, Kravets BB, Cherednikov EF. [Diagnostics of ulcerative forms of stomach cancer]. Voronezh. 2003:112. [In Russian].

*Corresponding author: Evgeniy $S$. Ovsyannikov, PhD, ScD. Department of Faculty Therapy, Voronezh State Medical University named after N.N. Burdenko. Voronezh, the Russian Federation. E-mail:ovses@yandex.ru
5. Cherednikov EF, Maleev YuV, Chernykh AV, Litovkina TE, Cherednikov EE, Shevtsov AN. [Modern views on the etiology and pathogenesis of ruptured hemorrhagic syndrome (Mallory-Weiss syndrome)]. Journal of Anatomy and Histology. 2016;(1):86-98. [Article in Russian].

6. Adianov VV, Cherednikov EF. [Optimization of treatment of gastroduodenal bleeding in patients with high surgical risk]. System Analysis and Management in Biomedical Systems. 2014;13(4):841-846. [Article in Russian].

7. Cherednikov EF, Barannikov SV, Romantsov MN, Popov AV. New aspects of preventive endoscopic hemostasis in the treatment of peptic ulcer bleeding in the experimental condition. The EPMA Journal. 2017;8(S1):45.

8. Deryaeva OG, Cherednikov EF. [Multimodality therapy of erosiveulcer gastroduodenal bleeding by patients in a multidisciplinary hospital]. System Analysis and Management in Biomedical Systems. 2014;13(3):725-730. [Article in Russian].

9. Cherednikov EF, Barannikov SV, Zhdanov AI, Moshurov IP, Polubkova GV, Maleev YuV, Ovsyannikov ES, Myachina DS. Combimed Use of biologically Active Hemostatic and Granulated Sorbent in Endoscopic Cytoprotective Hemostasis in Patients with Bleeding Gastroduodenal Ulcers. International Journal of Biomedicine. 2020;10(2):129-132. doi: 10.21103/ Article10(2)_OA8

10. Cherednikov EF, Glukhov AA, Romantsov MN, Maleev YuV, Barannikov SV, Shkurina IA, Vysotskaya AT, Ovsyannikov ES. Hemostatic Agents in Combination with Diovine for Local Treatment of Simulated Bleeding Gastric Ulcers. International Journal of Biomedicine. 2020;10(2):138141. doi: 10.21103/Article10(2)_OA10

11. Cherednikov EF., Budnevsky AV, Popov AV, Fursov KO. A new opinion on gastroduodenal bleeding preventon in patients with somatic patology. The EPMA Journal. 2017; 8(S1):46.

12. Savelyev VS. Guide to emergency surgery of abdominal organs. Moscow: Triad-X; 2004:640 pp. [In Russian].

13. Cherednikov EF, Barannikov SV, Fursov KO, Polubkova GV, Danilenko VI, Stepanov DS. [Healing of bleeding experimental defects of the stomach with topical anilovin and platelet-rich plasma]. Journal of Volgograd State Medical University. 2017;2(62):130-133. [Article in Russian].

14. Romantsov MN, Cherednikov EF, Danilenko VI, Stepanov DS, Fursov KO, Deryaeva AG. [Morphological Characteristics of Processes of Simulated Bleeding Gastric Defects Reparation in Treatment with Gelplastan and Diovin]. Journal of Anatomy and Histopathology. 2017;6(1):81-86. [Article in Russian].

15. Cherednikov EF, Barannikov SV, Maleev YuV, Fursov KO, Litovkina TE, Zakurdaev EI. [Experimental justification of the use of biologically active draining sorbent and plasma enriched by thrombocytes in treatment of bleeding defects of the stomach]. Journal of New Medical Technologies. 2017;24(2):114-118. [Article in Russian].

16. Cherednikov EF, Batkaev AR, Baev VE. The Reparative regeneration of erosive-ulcerative lesions of the stomach and duodenum in the local treatment of hydrophilic granular sorbents. System Analysis and Management in Biomedical Systems. 2005;4(2):224-225. [Article in Russian].

17. Barannikov SV, Litovkina TE, Fursov K O, Kuzmenok 
VA. [Experimental study of the possibility of using a biologically active draining sorbent and platelet-rich plasma in the endoscopic treatment of simulated bleeding stomach ulcers]. Postgraduate doctor. 2017;2.1(81):170-176. [Article in Russian].

18. Cherednikov EF, Barannikov SV, Maleev YuV, Fursov KO, Litovkina TE, Zakurdaev EI, Ovsyannikov ES. Experimental justification of using Aseptisorb-A and plateletrich plasma in endoscopic treatment of mold bleeding stomach defects. International Journal of Biomedicine. 2017;7(4):298301. doi: 10.21103/Article7(4)_OA5

19. Forrest JA, Finlayson ND, Shearman DJ. Endoscopy in gastrointestinal bleeding. Lancet. 1974 Aug 17;2(7877):3947. doi: 10.1016/s0140-6736(74)91770-x. PMID: 4136718.

20. Gorbashko AI. Diagnostics and treatment of blood loss.
Moscow: Meditsina. 1982:224 pp. [In Russian]. 21. Cherednikov EF, Romantsov MN, Ovchinnikov IF, Glukhov AA, Adianov VA, Vysotskaya AT; Voronezh State Medical University named after N. N. Burdenko [Method of endoscopic treatment of ulcerative gastroduodenal bleeding]. Patent for Invention RUS No. №2633588. Application No. 2015147321 dated 03.11.15; publ. 10.05.2017; Bulletin No. 13. [In Russian].

22. Cherednikov EF, Budnevsky AV, Barannikov SV, Fursov KO, Bondarenko AA, Cherednikov EE, Volkova IV; Voronezh State Medical University named after N. N. Burdenko. [Method for endoscopic stopping of gastrointestinal bleeding]. Patent for Invention RUS No. 2632771. Application No. 2016148270 dated 09.12.2016; publ. 09.10.2017; Bulletin No. 28. [In Russian]. 